\title{
Quantifying the distance to criticality under subsampling
}

\author{
Jens Wilting ${ }^{1 *}$, Viola Priesemann ${ }^{1,2}$ \\ From 24th Annual Computational Neuroscience Meeting: CNS*2015 \\ Prague, Czech Republic. 18-23 July 2015
}

Neuronal systems have been proposed to operate close to criticality. But how far from criticality are they precisely? We developed a novel method to determine the distance to criticality from data. Importantly, our method is reliable under subsampling, i.e. the experimental constraint that in many dynamical systems only a small fraction of all agents can be sampled. Thereby, our novel approach for the first time allows to determine the distance to criticality without bias from spiking activity in vivo, which in general is strongly subsampled.

In more detail, neuronal systems have been proposed to operate close to criticality, as power-law distributions of the avalanche size have been found for local field potentials from in vitro preparations [1], to human cortex [2]. Criticality is an attractive candidate state for neural dynamics, because in models criticality maximizes processing capacities [3]. However, it has been widely overlooked that criticality also comes with the risk of spontaneous runaway activity (epilepsy). Recent experiments suggest that spiking activity in rats, cats, and monkeys, is in a subcritical regime, keeping a safety-margin from criticality [4]. Quantifying the precise distance to criticality may help to shed light on how the brain maximizes its information processing capacities without risking runaway activity.

In neural systems, critical dynamics is usually studied in the context of branching processes with continuous drive [1], because they approximate well the functional propagation of spiking activity on the network [4]. The dynamics of branching processes are determined by the expected number of spikes $\sigma$ in postsynaptic neurons triggered by a single spike, showing either stationary dynamics (sub-critical, $\sigma<1$ ) or transient growth (super-critical, $\sigma>1$ ); for $\sigma=1$ branching processes are

\footnotetext{
* Correspondence: jwilting@nld.ds.mpg.de

${ }^{1}$ Max-Planck-Institute for Dynamics and Self-Organization, D-37077 Göttingen, Germany

Full list of author information is available at the end of the article
}

critical and generate the characteristic power law scaling. Methods to infer $\sigma$ from fully sampled systems are well established, however, subsampling [5] resulted in strongly biased estimates (Fig 1., empty symbols). To

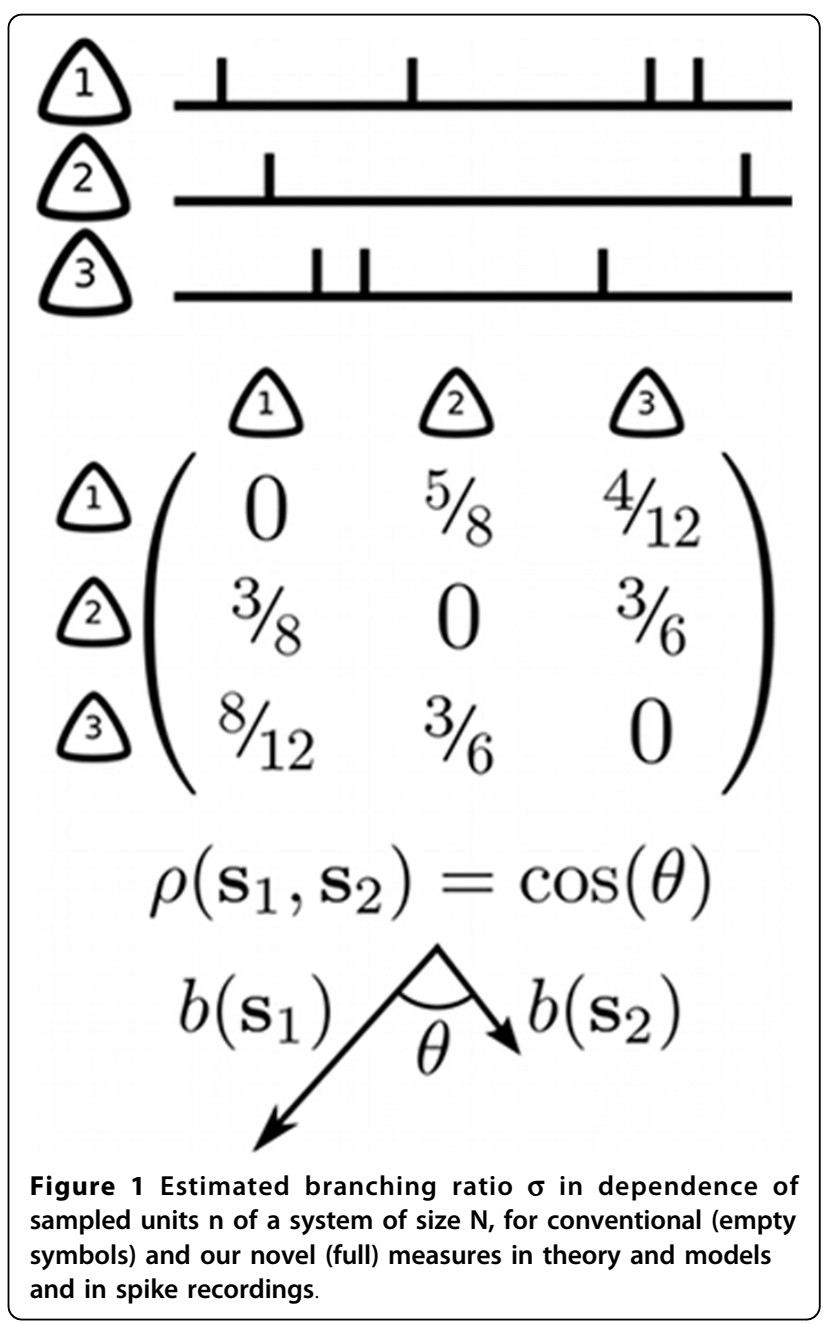


overcome this bias, we derived a novel measure, based on a multistep linear regression. This measure for the first time allows to quantify the distance to criticality even under strong subsampling (Fig., full symbols). Our method generalizes to auto-regressive processes with both additive and multiplicative noise, making it widely applicable. We validated our method by applying subsampling to simulated branching processes with invasion, and to a generic integrate-and-fire model. After validation, we applied this method to highly parallel spike recordings from macaque prefrontal cortex, cat visual cortex, and rat hippocampus. These analysis indicated that spiking activity is clearly subcritical $(0.97<\sigma$ $<0.99 ; \mathrm{N}=10$ experiments), and not critical.

\section{Authors' details}

1 Max-Planck-Institute for Dynamics and Self-Organization, D-37077

Göttingen, Germany. ${ }^{2}$ Bernstein Center for Computational Neuroscience,

University of Göttingen, D-37075 Göttingen, Germany.

Published: 18 December 2015

\section{References}

1. Beggs J, Plenz D: Neuronal avalanches in neocortical circuits. J Neurosci 2003, 23(35):11167-11177.

2. Priesemann V, Valerrame M, Wibral M, Le Van Quyen M: Neuronal avalanches differ from wakefulness to deep sleep - evidence from intracranial depth recordings in humans. PLoS Comp Biol 2013, 9(3) e1002985.

3. Boedecker J, Obst O, Lizier JT, Mayer NM, Asada M: Information processing in echo state networks at the edge of chaos. Theory Biosci 2012, 131(3):205-213.

4. Priesemann V, Wibral M, Valderrama M, Pröpper R, Le Van Quyen M, Geisel T, Triesch J, Nikolic D, Munk MHJ: Spike avalanches in vivo suggest a driven, slightly subcritical brain state. Front Syst Neurosci 2014, 8:108.

5. Priesemann $\mathrm{V}$, Munk MHJ, Wibral M: Subsampling effects in neuronal avalanche distributions recorded in vivo. BMC Neuroscience 2009, 10:40.

doi:10.1186/1471-2202-16-S1-O3

Cite this article as: Wilting and Priesemann: Quantifying the distance to criticality under subsampling. BMC Neuroscience 2015 16(Suppl 1):O3.

\section{Submit your next manuscript to BioMed Central} and take full advantage of:

- Convenient online submission

- Thorough peer review

- No space constraints or color figure charges

- Immediate publication on acceptance

- Inclusion in PubMed, CAS, Scopus and Google Scholar

- Research which is freely available for redistribution

Submit your manuscript at www.biomedcentral.com/submit 